\title{
The structure of 3,5-dimethylpyrazole/carboxylic acids co-crystals
}

\author{
Rosa M. Claramunt ${ }^{1}$, M. Ángeles García ${ }^{1}$, Concepción López ${ }^{* 1}$, and José Elguero ${ }^{\dagger 2}$ \\ ${ }^{1}$ Departamento de Química Orgánica y Bio-Orgánica, \\ Facultad de Ciencias, UNED, Senda del Rey, 9, \\ E-28040-Madrid, Spain \\ ${ }^{2}$ Instituto de Química Médica, CSIC, \\ Juan de la Cierva, 3, \\ E-28006 Madrid, Spain
}

E-mail:clopez@ccia.uned.es,rclaramunt@ccia.uned.es,iqmbe17@iqm.csic.es

Dedicated to our friend Professor Vladimir I. Minkin on his $70^{\text {th }}$ anniversary

(received 20 Jan 05; accepted 21 Mar 05; published on the web 08 Apr 05)

\begin{abstract}
Mixtures prepared either by mechanical grinding or by evaporation of equimolar amounts of 3,5dimethylpyrazole (1) and five carboxylic acids, four benzoic acids (2-5) and a pyrazole-4carboxylic acid (6), were studied by ${ }^{13} \mathrm{C}$ and ${ }^{15} \mathrm{~N}$ CPMAS NMR spectroscopy. In the cases corresponding to 1 and 2,4,6-trimethylbenzoic acid (2) or $\mathbf{1}$ and 2,6-dimethylbenzoic acid (3) the spectrum of the mixture is different from those of its components and we interpret them in terms of co-crystals formation through donor-acceptor hydrogen bonds. The remaining pairs behave as physical mixtures of both components, the spectrum of the mixture being the sum of the individual spectra. The origin of the differences is the much higher acidity of $o, o$-disubstituted benzoic acids.
\end{abstract}

Keywords: Pyrazoles, benzoic acids, hydrogen-bonds, proton transfer, ${ }^{13} \mathrm{C},{ }^{15} \mathrm{~N}, \mathrm{CPMAS}$ NMR

\section{Introduction}

The use of hydrogen bonding (HB) as a structural steering force can be considered as the most important strategy in crystal engineering. ${ }^{1}$ The patterns formed by carboxylic acids -cyclic dimers and open catemers- ${ }^{2}$ or by azole derivatives -cyclic dimers, trimers, tetramers and open catemers- have been widely investigated. ${ }^{3}$ Now we have focused our interest on how the presence of competitive hydrogen bond donor-acceptor groups can modify the HB patterns.

3,5-Dimethylpyrazole (1), a compound having both a hydrogen bond donor [HBD, the N(1)$\mathrm{H}$ ] and a hydrogen bond acceptor site [HBA, the $-\mathrm{N}(2)=]$ forms trimers $\mathbf{1}_{3}$ in the solid state 
(Figure 1). This structure confers to 1 the ability to transfer, in a concerted manner, the three $\mathrm{N}-$ $\mathrm{H}$ protons along the hydrogen bond (a phenomenon we named SSPT, solid-state proton transfer). ${ }^{4}$

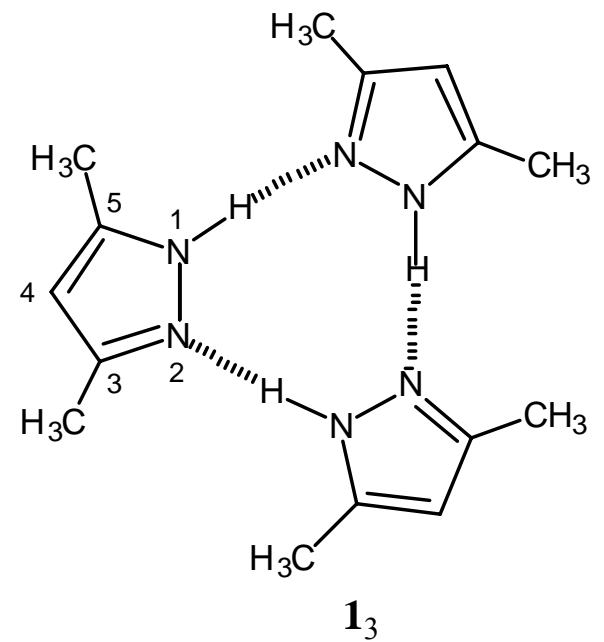

Figure 1. Trimer structure of $\mathbf{1}$ in the solid state.

Our present interest concerns the structure of the derivatives that result from mixing 3,5dimethylpyrazole (1) with other double hydrogen bonding compounds (HBD and HBA). Recently, we have proved ${ }^{5}$ that in the case of imidazoles [HBD, the N(1)-H and HBA, the $\mathrm{N}(3)=$ sites] only the 4,5-dimethylimidazole was able to disrupt the trimer $\mathbf{1}_{3}$ formed by 3,5 dimethylpyrazole in the solid state. As a continuation of our work concerning the determination of the X-ray molecular structure of 3,5-dimethylpyrazole (1)-2,4,6-trimethylbenzoic acid (2) cocrystal, ${ }^{6}$ in the present paper we report a study concerning carboxylic acids (HBD, the O-H and HBA, the $\mathrm{O}=$ sites).

This complex crystallizes forming a tetramer $\mathbf{1}_{2} \mathbf{2}_{2}$ (Figure 2) and, although a quadruple proton transfer is possible, such SSPT was not observed by solid-state ${ }^{15} \mathrm{~N}$ NMR. The hydrogenbonded network, as determined by crystallography, shows an additional $\mathrm{O}-\mathrm{H} \cdot \mathrm{O}-\mathrm{H}$ bond that breaks the symmetry. The chemical shifts of the nitrogen atoms of the $\mathbf{1}$ moiety appears at $181.7(\mathrm{NH})$ and $-115.3 \mathrm{ppm}(-\mathrm{N}=)$ while in trimer $\mathbf{1}_{3}$ they appear at -171.3 and $-96.8,{ }^{7}$ this difference was attributed to the replacement of $\mathrm{N}-\mathrm{H} \cdot \mathrm{N}$ by $\mathrm{N}-\mathrm{H} \cdot \mathrm{O}=\mathrm{C}$ hydrogen bonds. It is important to note that no proton transfer has occurred, that is, that the tetramer is not a pyrazolium benzoate salt. 


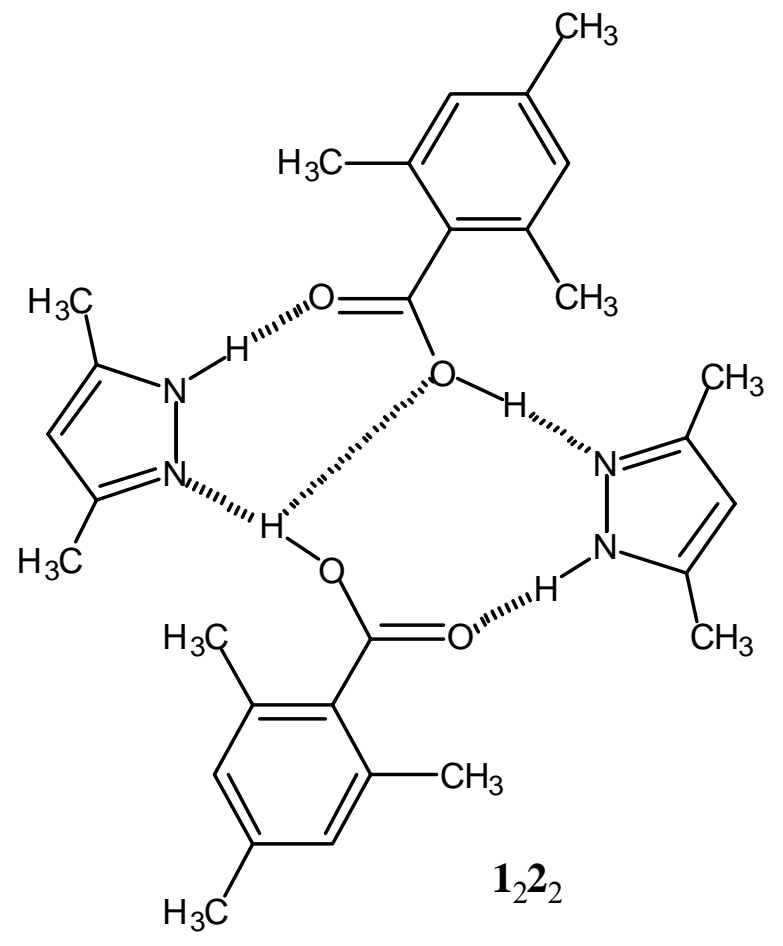

Figure 2. Tetramer structure of $[\mathbf{1}+\mathbf{2}]$ in the solid state.

When searching within the Cambridge Structural Database (November 2003 version) only another paper concerning this problem can be found. In this publication, ${ }^{8}$ also from our group, the crystal and molecular structures formed by 1,1'-binaphthyl-2,2'-dicarboxylic acid (BNDA) with 3,5-dimethylpyrazole (1) and pyrazole (7) are described. The most significant result is that the structure depends on the stoichiometry, when it is 1:1, the resulting structure is a salt and when it is 1:2, a neutral complex is obtained both for $\mathbf{1}$ and for $\mathbf{7}$. This result proves that the neither the acidity of the acid nor the basicity of the pyrazole alone determines the structure (salt or complex) of the resulting mixture.

\section{Results and Discussion}

When trying to prepare equimolar mixtures of 3,5-dimethylpyrazole (1) with the five carboxylic acids (2-6) depicted in Figure 3, three main questions arise:

1. Is the new compound a molecular complex or a salt (pyrazolium carboxylate)?

2. If the compound is a neutral complex, does the SSPT occur?

3. Is the stoichiometry of the complex a 1:1 or a higher one (for instance, 2:2)? 

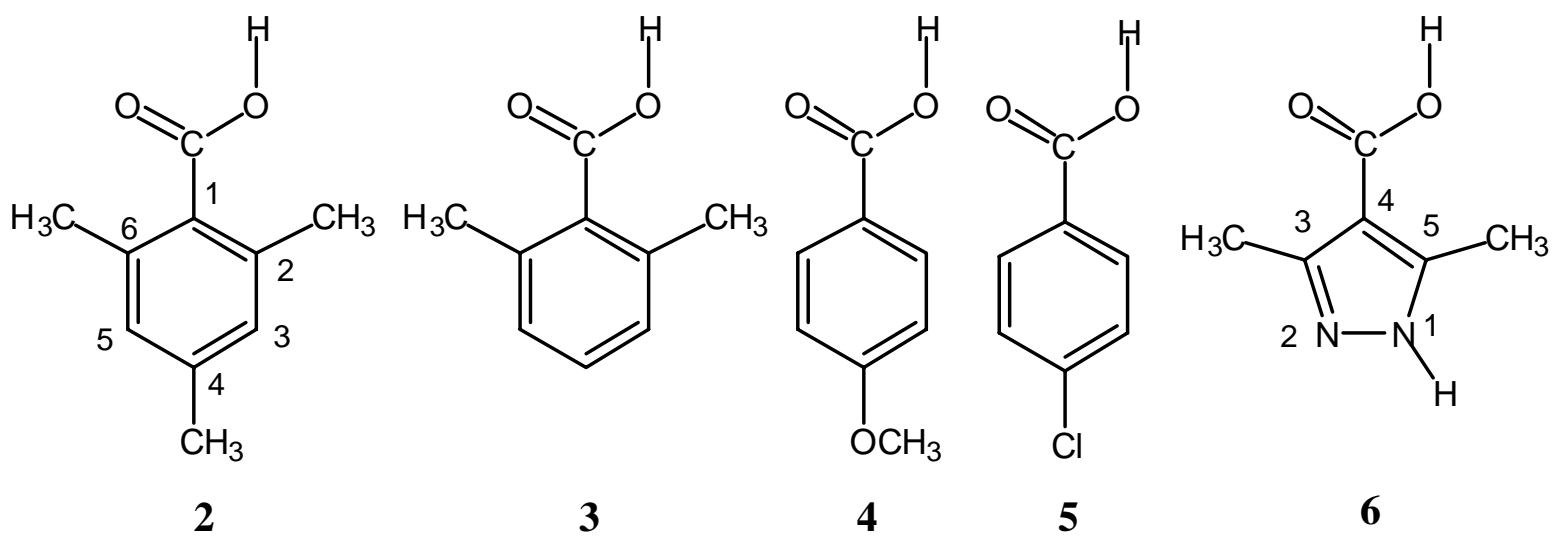

Figure 3. The five carboxylic acids.

The ${ }^{13} \mathrm{C}$ NMR data of 2,4,6-trimethylbenzoic acid (2), 2,6-dimethylbenzoic acid (3) and its sodium salt $3^{-}, p$-methoxybenzoic acid (4), $p$-chlorobenzoic acid (5) and 3,5-dimethyl-4-pyrazole carboxylic acid (6) are gathered in Table 1, while in Table 2 the data of 3,5-dimethylpyrazole (1) are reported.

Table 1. ${ }^{13} \mathrm{C}$ chemical shifts of carboxylic acids 2-6 $(*,+,+$ : pairs of unassigned signals) at $300 \mathrm{~K}$

\begin{tabular}{|c|c|c|c|c|c|c|c|c|c|c|}
\hline Compound & $\mathrm{C}-1$ & $\mathrm{C}-2$ & $\mathrm{C}-3$ & C-4 & C-5 & $\mathrm{C}-6$ & Me-2 & $\mathrm{Me}-4$ & Me-6 & $\mathrm{C}=\mathrm{O}$ \\
\hline $2 \mathrm{CDCl}_{3}$ & 129.3 & 136.2 & 128.8 & 140.1 & 128.8 & 136.2 & 20.4 & 21.1 & 20.4 & 176.2 \\
\hline 2 CPMAS & 128.3 & $137.8^{\dagger}$ & $129.2 *$ & 140.2 & $130.2 *$ & $138.6^{\dagger}$ & $19.6^{\ddagger}$ & 21.4 & $20.3^{\star}$ & 176.4 \\
\hline $3 \mathrm{CDCl}_{3}$ & 132.3 & 135.6 & 127.9 & 129.9 & 127.9 & 135.6 & 20.2 & ---- & 20.2 & 175.8 \\
\hline 3 DMSO$^{-d_{6}}$ & 135.5 & 133.4 & 127.3 & 128.6 & 127.3 & 133.4 & 19.2 & --- & 19.2 & 170.7 \\
\hline 3 CPMAS & 130.4 & $137.4^{*}$ & 127.3 & 129.0 & 127.3 & $135.8^{*}$ & $20.6^{\dagger}$ & ---- & $21.3^{\dagger}$ & 176.7 \\
\hline $3^{-} \mathrm{CDCl}_{3}$ & 133.9 & 134.8 & 127.6 & 129.2 & 127.6 & 134.8 & 19.9 & ---- & 19.9 & 174.4 \\
\hline $3^{-}$DMSO$_{-d_{6}}$ & 144.3 & 131.4 & 126.3 & 124.9 & 126.3 & 131.4 & 19.6 & ---- & 19.6 & 173.7 \\
\hline $3^{-}$CPMAS & 139.9 & $130.7 *$ & 126.2 & 126.2 & 126.2 & $131.7 *$ & $19.7^{\dagger}$ & ---- & $20.9^{\dagger}$ & 182.0 \\
\hline$\Delta \delta\left(3^{-}-3\right) \mathrm{CP}$ & 9.5 & -6.7 & -1.1 & -2.8 & -1.1 & -4.1 & -0.2 & ---- & -0.4 & 5.3 \\
\hline 4 CPMAS $^{\mathrm{a}}$ & 120.1 & $130.8^{*}$ & $115.9^{\dagger}$ & 164.9 & $110.1^{\dagger}$ & $131.7 *$ & ---- & ---- & ---- & 173.0 \\
\hline 5 CPMAS & 127.2 & 131.9 & $129.9 *$ & $\mathrm{~b}$ & $130.8^{*}$ & 131.9 & --- & ---- & ---- & 172.8 \\
\hline 6 CPMAS & ---- & ---- & 146.8 & 109.3 & 146.8 & ---- & $14.3^{\mathrm{c}}$ & ---- & $14.3^{\mathrm{c}}$ & 166.3 \\
\hline
\end{tabular}

${ }^{\mathrm{a}} \mathrm{MeO}$ : $56.6 \mathrm{ppm}^{\mathrm{b}}{ }^{\mathrm{b}}$ Not observed. ${ }^{\mathrm{c}} \mathrm{Me}-3$ and Me-5. 
Table 2. ${ }^{13} \mathrm{C}$ and ${ }^{15} \mathrm{~N}$ chemical shifts of $\mathbf{1}$ in the solid state at $300 \mathrm{~K}$

\begin{tabular}{cccccccc}
\hline Compound & $\mathrm{C}-3$ & $\mathrm{C}-4$ & $\mathrm{C}-5$ & $\mathrm{Me}-3$ & $\mathrm{Me}-5$ & $\mathrm{~N}-1$ & $\mathrm{~N}-2$ \\
\hline $\mathbf{1}^{\mathrm{a}}$ & $143.7^{\mathrm{b}}$ & 104.9 & $143.7^{\mathrm{b}}$ & $11.8^{\mathrm{b}}$ & $11.8^{\mathrm{b}}$ & $-134^{\mathrm{c}}$ & $-134^{\mathrm{c}}$ \\
$\mathbf{1}$ & $143^{\mathrm{c}}$ & 104.9 & $143^{\mathrm{c}}$ & $11.8^{\mathrm{b}}$ & $11.8^{\mathrm{b}}$ & $-170.5^{\mathrm{b}}$ & $-97.6^{\mathrm{b}}$ \\
$\mathbf{1}^{\mathrm{d}}$ & 147.4 & 104.6 & 139.1 & 12.6 & 10.5 & -170.6 & -97.7 \\
$\mathbf{1 H}^{+}$(HCl) & 147.6 & 106.6 & 142.8 & $11.3^{*}$ & $11.9^{*}$ & -184.3 & -182.7 \\
& & & & & & -184.9 & -183.4 \\
$\mathbf{1 H}^{+}(\mathrm{TFAA})$ & $146.9^{*}$ & 105.6 & $145.6^{*}$ & $10.8^{\dagger}$ & $10.1^{\dagger}$ & -187.4 & -180.0 \\
{$\left[\mathbf{1 H}^{+}(\mathrm{TFAA})-\mathbf{1}^{\mathrm{d}}\right]$} & -0.5 & 1.0 & 6.5 & -1.8 & -0.4 & -16.8 & -82.7 \\
\hline
\end{tabular}

${ }^{\mathrm{a}} 353 \mathrm{~K} .{ }^{\mathrm{b}}$ br. ${ }^{\mathrm{c}} \mathrm{vbr} .{ }^{\mathrm{d}} 200 \mathrm{~K}$.

For eventual occurrence of proton transfer, we have measured the anion of 3 (Table 1) and the cation of $\mathbf{1}$ (Table 2, for an NMR study of the protonation of pyrazoles ${ }^{11}$ ). This allowed to determine the following most important chemical shift effects:

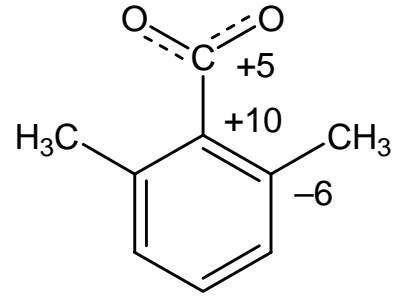

$\Delta \delta\left(3^{-}-3\right)$

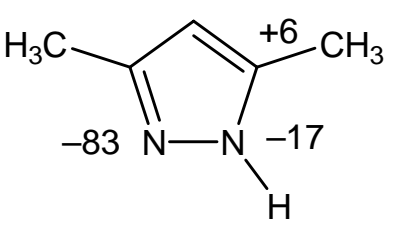

$\Delta \delta\left(\mathbf{1} \mathbf{H}^{+}-\mathbf{1}\right)$

Figure 4. Chemical shift effects in ppm due to the deprotonation of $\mathbf{3}$ and the protonation of $\mathbf{1}$.

The $[\mathbf{1}+\mathbf{4}],[\mathbf{1}+\mathbf{5}]$ and $[\mathbf{1}+\mathbf{6}]$ mixtures are physical mixtures and the CPMAS spectra are the sum of the spectra of individual components, therefore, they were only studied by ${ }^{13} \mathrm{C}$ NMR at $50.32 \mathrm{MHz}$.

The fact that the ${ }^{13} \mathrm{C}$ CPMAS spectrum of the $[\mathbf{1}+\mathbf{6}]$ mixture shows no difference from the individual spectra of 3,5-dimethylpyrazole (1) and 3,5-dimethylpyrazole-4-carboxylic acid (6) is of particular relevance because pyrazole-4-carboxylic acid (8) also shows SSPT although by a different mechanism. ${ }^{12}$ The data reported in Table 1 , namely the asymmetry of the positions 3 and 5 , seems to indicate that a similar phenomenon occurs in 6 .

The $[\mathbf{1}+\mathbf{2}]$ mixture (1:1), actually $\mathbf{1}_{2} \mathbf{2}_{2}$, was studied again. In ${ }^{15} \mathrm{~N}$ CPMAS NMR (40.60 $\mathrm{MHz})$ we obtain a signal at $-182.8 \mathrm{ppm}(-181.7, \mathrm{~N}-\mathrm{H}[6])$ and two signals at -116.8 and -113.9 $(-115.3,-\mathrm{N}=[6])$. The better resolution of the new instrument allows the observation of a splitting of the $\mathrm{N}(2)$ signal, possibly due to the small asymmetry of the tetramer (additional O$\mathrm{H} \cdot \mathrm{O}-\mathrm{H}$ bond). The ${ }^{13} \mathrm{C}$ CPMAS NMR was also recorded at $100.73 \mathrm{MHz}$. The chemical shifts in 
ppm are: 176.1/174.8 $(\mathrm{C}=\mathrm{O}), 147.3 / 146.7$ (pyrazole C-3), 140.0/139.4/139.0 (benzoic C-4 and C6), 135.6/135.1 (benzoic C-2), 133.5/132.9 (pyrazole C-5), 129.1 (benzoic C-3 and C-5), 128.3 (benzoic C-1), 105.4/104.8 (pyrazole C-4), 21.5/20.0/19.4/18.8 (benzoic Me-4, Me-2 and Me-6) and 12.1/10.3/9.5 (pyrazole Me-3 and Me-5). These values agree with the $\mathbf{1}_{2} \mathbf{2}_{2}$ structure.

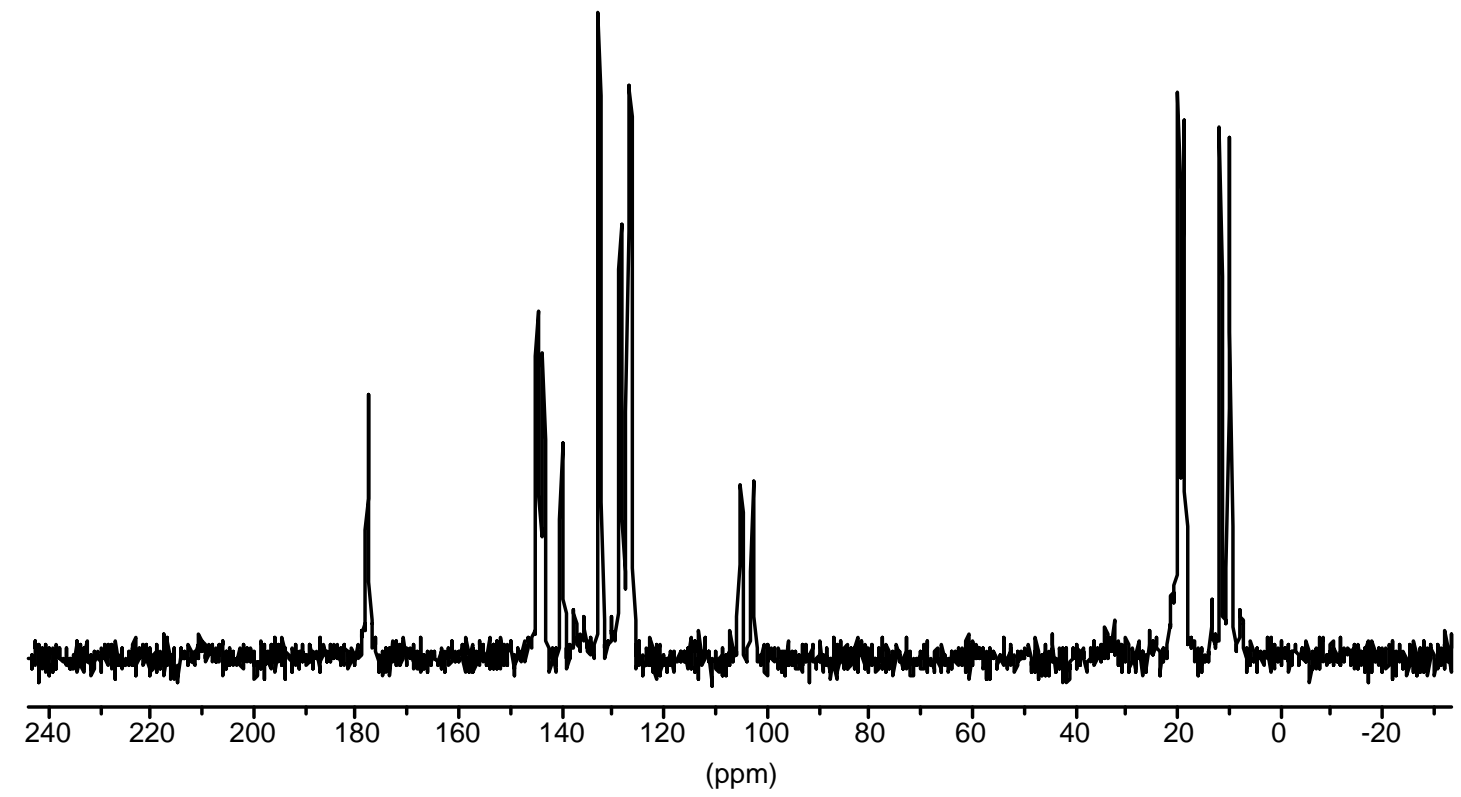

Figure 5. ${ }^{13} \mathrm{C}$ CPMAS NMR spectrum at $100.73 \mathrm{MHz}$ of the $1: 1[\mathbf{1}+\mathbf{3}]$ mixture.

The $[\mathbf{1}+3]$ mixture $(1: 1)$ is very interesting. First of all it has a 1:1 (or 2:2) stoichiometry. By analogy of the $\mathbf{1}_{2} \mathbf{2}_{2}$ neutral complex previously reported (Figure 2) we assume that it correspond to a $\mathbf{1}_{2} \mathbf{3}_{2}$ tetramer. Its ${ }^{13} \mathrm{C}$ and ${ }^{15} \mathrm{~N}$ CPMAS NMR spectra reported in Figure 5 and 6 are in agreement with this hypothesis. 


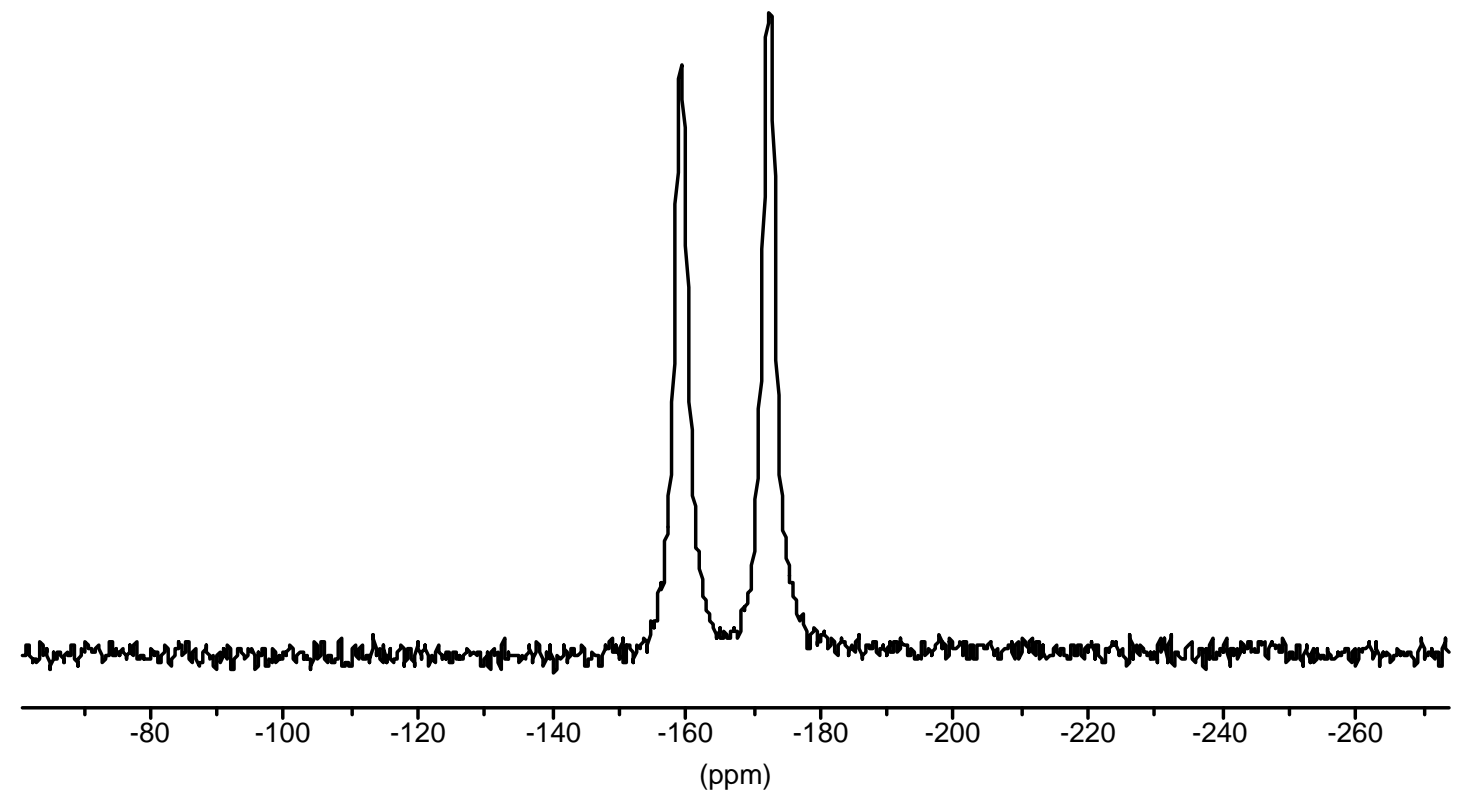

Figure 6. ${ }^{15} \mathrm{~N}$ CPMAS NMR spectrum at $40.59 \mathrm{MHz}$ of the $[\mathbf{1}+\mathbf{3}]$ mixture.

In Figure 7 we have represented four possible tetramers corresponding to $\mathbf{1}_{2} \mathbf{3}_{2}$, all of them without the supplementary $\mathrm{O}-\mathrm{H} \cdot \mathrm{O}-\mathrm{H}$ HB present in $\mathbf{1}_{2} \mathbf{2}_{2}$ (Figure 2) together with the predicted ${ }^{13} \mathrm{C}$ and ${ }^{15} \mathrm{~N}$ chemical shifts based on model compounds. Structure [a] corresponds to a situation with hydrogen bonding and no SSPT, note that the values differ from those of $\mathbf{1}_{2} \mathbf{2}_{2}$, in particular the pyrazole C-5 (133.2 instead of $139.1 \mathrm{ppm})$ and the ${ }^{15} \mathrm{~N}$ NMR signals $(-182.8 /-115.4$ instead of $-170.6 /-97.7 \mathrm{ppm})$. Structure [b] corresponds to a situation with neutral entities and SSPT, its chemical shifts being the average of the ones for the previous structure. Tetramer [c] is obtained from [a] with two protons transferred but without SSPT, that is, it is a double pyrazolium benzoate. Finally, [d] corres-ponds to an intermediate situation between [a] and [c], i.e., only one proton transferred and no SSPT.

The experimental data for 3,5-dimethylpyrazole: ${ }^{15} \mathrm{~N}$ NMR -159.3 and $-172.6 \mathrm{ppm} ;{ }^{13} \mathrm{C}$ NMR 9.9 and 11.6 ppm (methyl groups), 102.7 and 105.1 ppm (C-4), 143.5 and 144.5 ppm (C-3 and C-5); 2,6-dimethylbenzoic acid part: 18.8 and 19.7 ppm (methyl groups), 126.8 ppm (C-3' and C-5'), 128.4 ppm (C-4'), 132.5 ppm (C-2' and C-6'), 139.9 ppm (C-1') and 177.5 ppm $(\mathrm{C}=\mathrm{O})$. 

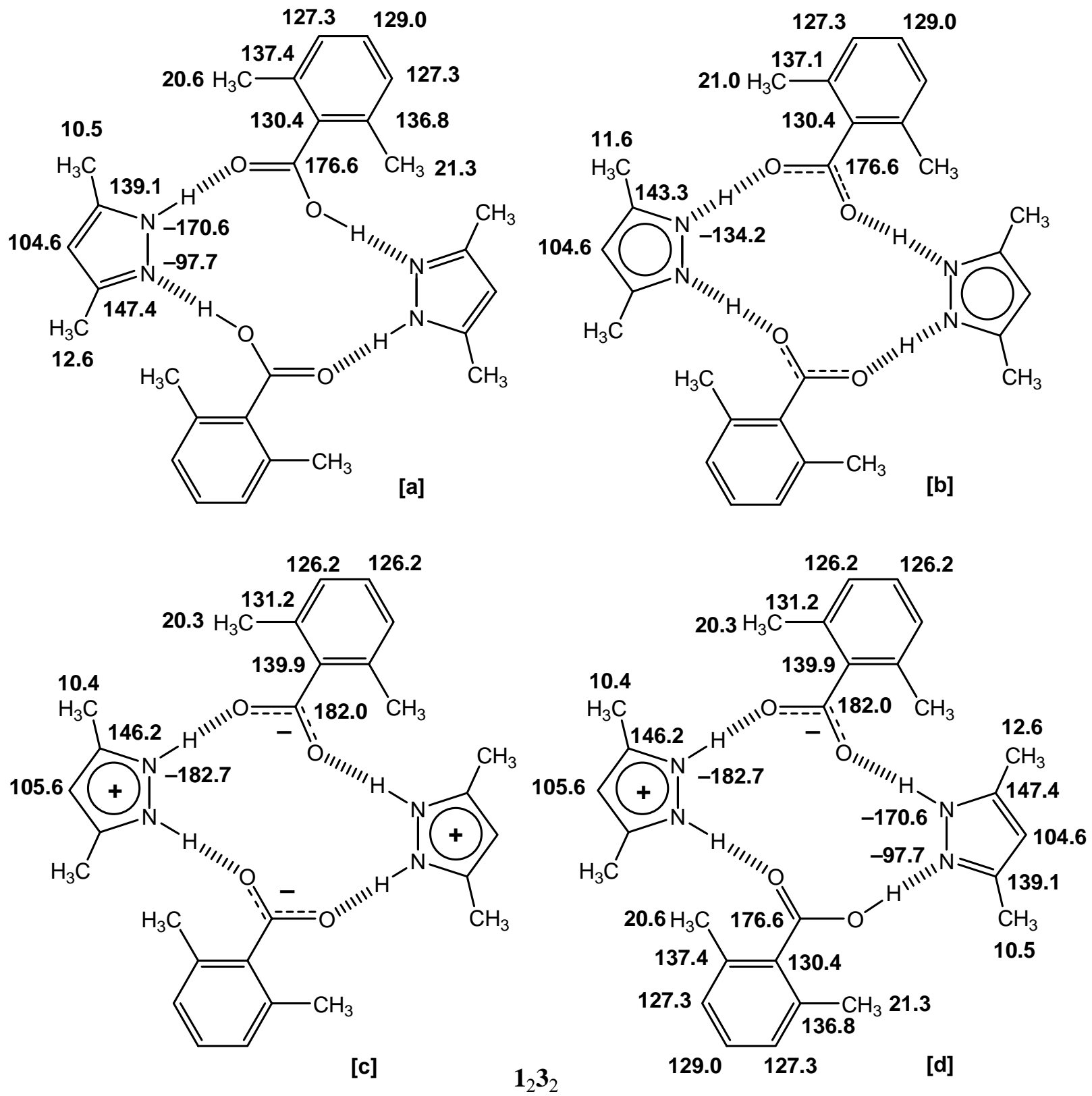

Figure 7. Estimated ${ }^{13} \mathrm{C}$ and ${ }^{15} \mathrm{~N}$ CPMAS NMR chemical shifts (ppm) of possible models of the $\mathbf{1}_{2} \mathbf{3}_{2 .}$.

None of these structures explain the observed chemical shifts for $\mathbf{1}_{2} \mathbf{3}_{2}$. Therefore, we tentatively propose a rapid equilibrium (SSPT) between two identical d structures, d1 and d2 (Figure 8). Although the observed asymmetry at the $(2 \& 6)$ and $(3 \& 5)$ positions of the benzoic acids might be the result of many different sorts of crystalline environments, we cannot find any alternative explanation for the ${ }^{15} \mathrm{~N}$ chemical shifts. 


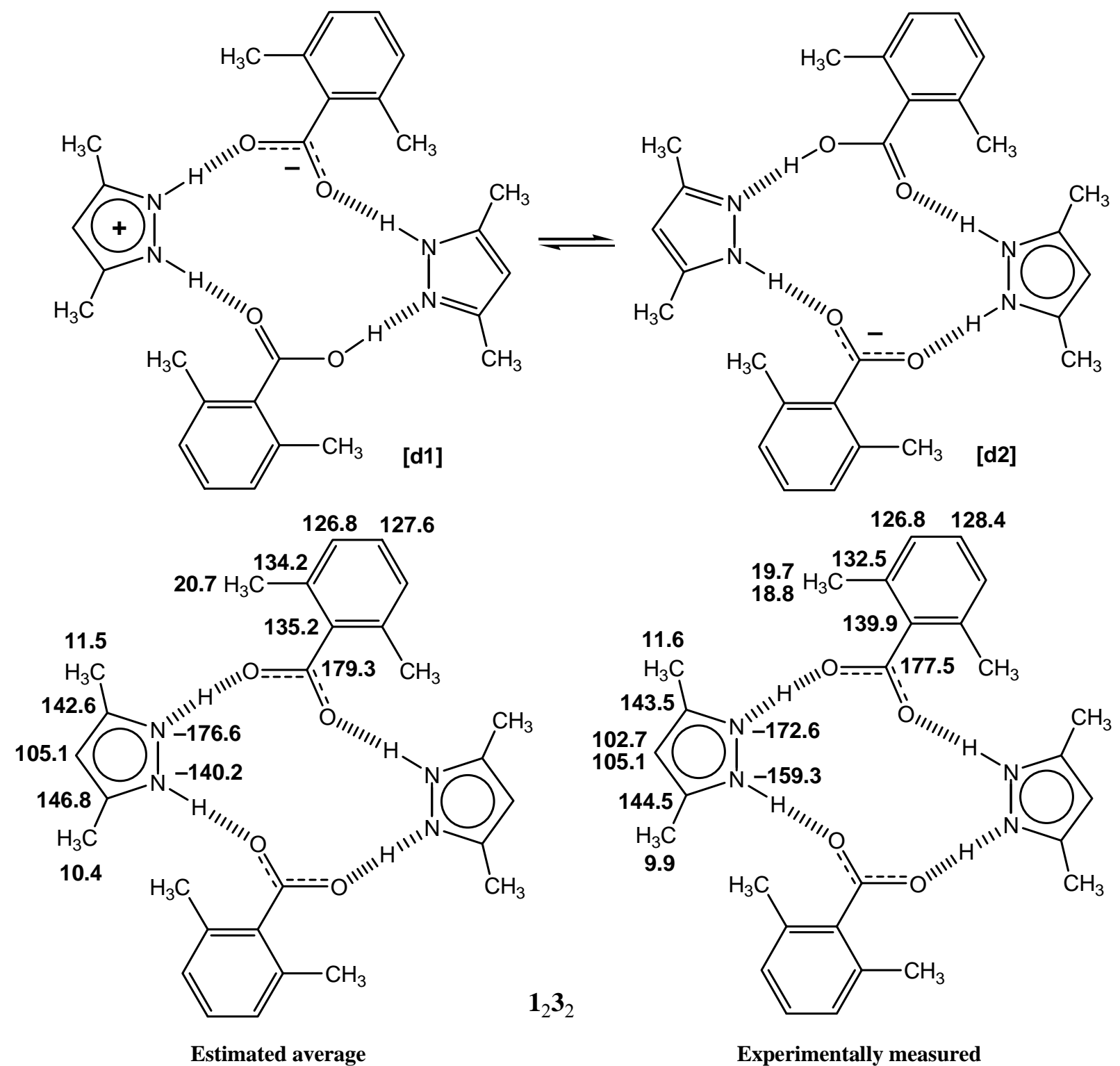

Figure 8. Estimated and measured ${ }^{13} \mathrm{C}$ and ${ }^{15} \mathrm{~N}$ CPMAS NMR chemical shifts (ppm) of $\mathbf{1}_{2} \mathbf{3}_{2}$.

Unfortunately, the $[\mathbf{1}+\mathbf{3}]$ mixture is a viscous oil that solidifies on standing after several weeks but not in a crystalline form, preventing to determine its structure by X-ray crystallography. The reason why both 2,4,6-trimethylbenzoic acid (2) and 2,6-dimethylbenzoic acid (3) destroy the 3,5-dimethylpyrazole trimer $\mathbf{1}_{3}$ to form new supramolecular structures while the other carboxylic acids 4-6 did not is almost certainly related to the much higher acidities of the first two. Here are the experimental $\mathrm{p} K_{\mathrm{a}} \mathrm{s}$ of some benzoic acids ${ }^{13}$ : benzoic acid 4.19, $p$ methoxybenzoic acid (4) 4.47, p-chlorobenzoic acid (5) 3.98, 2,4,6-trimethylbenzoic acid (2) 3.45 and 2,6-dimethylbenzoic acid (3) 3.35, p-nitrobenzoic acid 3.44. We predict that $p$ nitrobenzoic acid would behave similarly to 2 and $\mathbf{3}$ when mixed with $\mathbf{1}$. 


\section{Experimental Section}

Sample Preparation. The mixtures were prepared using two different methods: i) both components were mixed in a ceramic mortar and ground with a pestle for 10 min until a homogeneous mixture was obtained, ii) the compounds were dissolved in ethanol and the solvent was removed in vacuum. All compounds were commercially available, except 3,5dimethylpyrazole-4-carboxylic acid (6), which was prepared by hydrolysis of the corresponding ethyl ester. ${ }^{9}$

\section{NMR Spectroscopy}

Solid state ${ }^{13} \mathrm{C}(50.32 \mathrm{MHz})$ and ${ }^{15} \mathrm{~N}(20.28 \mathrm{MHz})$ CPMAS NMR spectra have been obtained with a Bruker AC-200 spectrometer at $298 \mathrm{~K}$ and a 7-mm Bruker DAB-7 probe head, which achieves rotational frequencies of $c a \cdot 3.5-4.5 \mathrm{kHz}$. Samples were carefully packed in a $\mathrm{ZrO}_{2}$ rotors with Kel-F end-caps and the standard CPMAS pulse sequence was used. To observe only the quaternary C-atoms, we run the $N Q S$ (Non-Quaternary Suppression) experiments by conventional cross-polarization (CP) at different contact times and with the dipolar dephased technique. ${ }^{10}{ }^{13} \mathrm{C}$ spectra were originally referenced to a glycine sample and then the chemical shifts were recalculated to the $\mathrm{Me}_{4} \mathrm{Si}$ (for the carbonyl atom $\delta$ (glycine) $=176.1 \mathrm{ppm}$ ) and ${ }^{15} \mathrm{~N}$ spectra to ${ }^{15} \mathrm{NH}_{4} \mathrm{Cl}$ and then converted to nitromethane scale using the relationship: $\delta$ ${ }^{15} \mathrm{~N}$ (nitromethane $)=\delta{ }^{15} \mathrm{~N}($ ammonium chloride $)-338.1 \mathrm{ppm}$. Some spectra were recorded again using a $400 \mathrm{MHz}$ instrument: solid state ${ }^{13} \mathrm{C}(100.73 \mathrm{MHz})$ and ${ }^{15} \mathrm{~N}(40.59 \mathrm{MHz})$ CPMAS NMR spectra have been obtained on a Bruker WB-400 spectrometer at $300 \mathrm{~K}$ using a $4 \mathrm{~mm} \mathrm{DVT}$ probehead at rotational frequencies of $c a .5-10 \mathrm{kHz}$.

\section{Acknowledgments}

This work has been financed by DGICYT (BQU2003-00976). One of us (C.L.) tanks the UNED for economic support (project number 2003I/PUNED/21). We are much grateful to Dr. Lourdes Infantes from CSIC who helped us in searching through the Cambridge Structural Data Base. This manuscript owes much to the referee comments about the acidity of ortho-substituted benzoic acids.

\section{References}

1. (a) Desiraju, G. R. Crystal Engineering: The Design of Organic Solids. Elsevier: Amsterdam, 1989. (b) Desiraju, G. R. Perspectives in Supramolecular Chemistry: The Crystal as a Supramolecular Entity; Wiley: Chichester, 1996.

2. (a) Leiserowitz, L. Acta Crsytallogr., Sect. C 1976, 32, 775. (b) Eichhorst-Gerner, K.; Stabel, 
A.; Moessner, G.; Declerq, D.; Valiyaveettil, S.; Enkelmannn, V.; Müllen, K.; Rabe, J. P. Angew. Chem. 1996, 108, 1599; idem, Angew. Chem., Int. Ed. 1996, 108, 1492. (c) Ibragimov, B. T.; Beketov, K. M.; Makhkamov, K. K.; Weber, E. J. Chem. Soc., Perkin Trans. 2 1997, 1349. (d) Beketov, K. M.; Weber, E.; Seidel, J.; Köhnke, K.; Makhkamov, K. K.; Ibragimov, B. T. J. Chem. Soc., Chem. Commun. 1999, 91. (e) Ibrogimov, B. T.; Beketov, K. M.; Weber, E. J. Supramol. Chem. 2002, 2, 353.

3. (a) Baldy, A.; Elguero, J.; Faure, R.; Pierrot, M.; Vincent, E.-J. J. Am. Chem. Soc. 1985, 107, 5290. (b) Foces-Foces, C.; Alkorta, I.; Elguero, J. Acta Cryst., Sect. B 2000, 56, 1018. (c) Claramunt, R. M.; López, C.; García, M. A.; Pierrot, M.; Giorgi, M.; Elguero, J. J. Chem. Soc., Perkin Trans. 2 2000, 2049. (d) García, M. A.; López, C.; Peters, O.; Claramunt, R. M.; Klein, O.; Schagen, D.; Limbach, H.-H.; Foces-Foces, C.; Elguero, J. Magn. Reson. Chem. 2000, 38, 604. (e) Trofimenko, S.; Rheingold, A. L.; Liable-Sands, L. M.; Claramunt, R. M.; López, C.; Santa María, M. D.; Elguero, J. New. J. Chem. 2001, 25, 819. (f) Claramunt, R. M.; López, C.; García, M. A.; Otero, M. D.; Torres, M. R.; Pinilla, E.; Alacrcón, S. H.; Elguero, J. Ibid. 2001, 25, 1061. (g) García, M. A.; López, C.; Claramunt, R. M.; Kenz, A.; Pierrot, M.; Elguero, J. Helv. Chim. Acta 2002, 85, 2763.

4. Elguero, J.; Cano, F. H.; Foces-Foces, C.; Llamas-Saiz, A. L.; Limbach, H.-H.; AguilarParrilla, F.; Claramunt, R. M.; López, C. J. Heterocycl. Chem. 1994, 31, 695.

5. Claramunt, R. M.; García, M. A.; López, C.; Elguero, J. Central Eur. J. Chem. 2004, 2, 660.

6. Foces-Foces, C.; Infantes, L.; Aguilar-Parrilla, F.; Golubev, K. S.; Limbach, H.-H.; Elguero, J. J. Chem. Soc., Perkin Trans. 2 1996, 349.

7. Klein, O.; Aguilar-Parrilla, F.; López, J. M.; Jagerovic, N.; Elguero, J.; Limbach. H.-H. J. Am. Chem. Soc. 2004, 126, 11718.

8. Hager, O.; Llamas-Saiz, A. L.; Foces-Foces, C.; Claramunt, R. M.; López, C.; Elguero, J. Helv. Chim. Acta 1999, 82, 2213.

9. Mokhtar, H. M.; Tag El-Din, A. T. F.; Deshesh, M. A. T. Pakistan J. Sci. Ind. Res. 1987, 30, 1.

10. Opella, S. J.; Frey, M. H. J. Am. Chem. Soc. 1979, 101, 5855.

11. Claramunt, R. M.; López, C.; García, M. A.; Denisov, G. S.; Alkorta, I.; Elguero, J. New J. Chem. 2003, 27, 734.

12. Foces-Foces, C.; Echevarría, A.; Jagerovic, N.; Alkorta, I.; Elguero, J.; Langer, U.; Klein, O.; Minguet-Bonvehí, M.; Limbach, H.-H. J. Am. Chem. Soc. 2001, 123, 7898.

13. Tables of Rate and Equilibrium Constants of Heterolytic Organic Reactions, Palm, V. A., Ed.; Moscow, 1975; Vol. 1. 